\title{
Airflow modeling analysis of the Athens airport train station
}

\author{
M. Gr. Vrachopoulos ${ }^{1}$, F.K. Dimokritou ${ }^{2}$, A.E. Filios ${ }^{3}$ \& A. Fatsis ${ }^{1}$ \\ ${ }^{I}$ Technological University of Chalkis, \\ Department of Mechanical Engineering, Greece \\ ${ }^{2}$ Harvard University, Environmental Science and Engineering, USA \\ ${ }^{3}$ ASPAITE University, Department of Mechanical Engineering, Greece
}

\begin{abstract}
The present work aims to investigate the maximum $\mathrm{CO}$ distribution in the Athens-Greece airport train station platform for long-term exposure. A model based on the numerical solution of the three-dimensional flow field of the Athens-Greece airport train station was developed for this reason The work was performed using the CFD package called FLOVENT ${ }^{\mathbb{R}}$ V3.2.

The initial study of the $\mathrm{CO}$ level at the train station was performed without mechanical ventilation at the train station platform. Three different cases were examined by varying the wind magnitude and direction. Subsequently, four extra scenarios were examined with and without mechanical ventilation. The results obtained from the scenario with mechanical ventilation were compared to the ones from the scenario without mechanical ventilation. In all the above cases, the $\mathrm{CO}$ emissions from the vehicles in the two nearby highways were also taken into account. It is concluded that the maximum CO level in the case with mechanical ventilation is higher than in the case without. This is due to recirculation zones that create locally high levels of $\mathrm{CO}$ in the platform area. On the other hand, the average level of $\mathrm{CO}$ is lower at the platform with the ventilation on.

Keywords: emissions level, mechanical ventilation, numerical prediction.
\end{abstract}

\section{Introduction}

A study undertaken to investigate the CO levels in the Athens-Greece Airport train station platform is presented in the present article. Several external wind conditions will be studied and these will be compared to cases with mechanical 
ventilation at the train station platform. The work was performed using the Computational Fluid Dynamics tool called FLOVENT® V3.2.

The primary objective of the study is to determine the CO levels on the train station platform under different external wind conditions. The $\mathrm{CO}$ level should not exceed $25 \mathrm{ppm}$ for long term exposure (i.e. $8 \mathrm{hrs}$ ), per World Health Organization Recommendations, [1].

\section{Model description and results}

Airflow and heat transfer within a fluid are governed by the principles of conservation of mass, momentum and thermal energy. These conservation laws may be expressed in terms of partial differential equations, the solution of which forms the basis of computational fluid dynamics (CFD).

The finite volume based approach was used, requiring the region modelled to be sub-divided into a number of small volumes or grid cells. During the program solution, the developed CFD model integrates the relevant differential conservation equations [2] over each computational grid cell, assembling a set of algebraic equations which relate the value of the variable in a cell to the value in adjacent cells. Since the equations display strong coupling (variables are dependant upon surrounding values and other variables) the solution is carried out iteratively.

\subsection{Baseline cases}

\subsubsection{Model assumptions}

The following assumptions were done in the present study:

- The wind speed is $15 \mathrm{~m} / \mathrm{s}$ from the North direction. A velocity profile was applied at the North face of the solution domain, which varied from $1 \mathrm{~m} / \mathrm{s}$ at ground to $15 \mathrm{~m} / \mathrm{s}$ at $10 \mathrm{~m}$. This is based upon local meteorological data. Additional Iterations were performed with different wind speeds and directions. See Table 1.

- Ambient temperature is $32 \mathrm{C}$.

- Total CO release rate is $1.9 \mathrm{E}-3 \mathrm{~kg} / \mathrm{s}$.

- 400 cars are releasing $\mathrm{CO}$ at a rate $2.61 \mathrm{~g} / \mathrm{mile}$.

- The CO source was uniformly distributed along the roadways.

- Small items, which do not affect the general airflow patterns, were not included in the model.

- Thermal loading from lights, people, trains, etc, were considered insignificant and were not included.

- The CFD solution domain size is $350 \mathrm{~m} \times 350 \mathrm{~m} \times 50 \mathrm{~m}$ with 801,248 grid cells. The maximum aspect ration is 15.6 .

- The model was solved on a system with dual 2.4 GHz CPUs and 2.0 G RAM. The model solved in approximately 550 iterations and in 5.1 hours.

\subsubsection{Model geometry}

The model geometry and boundary conditions are shown in the following figure. 


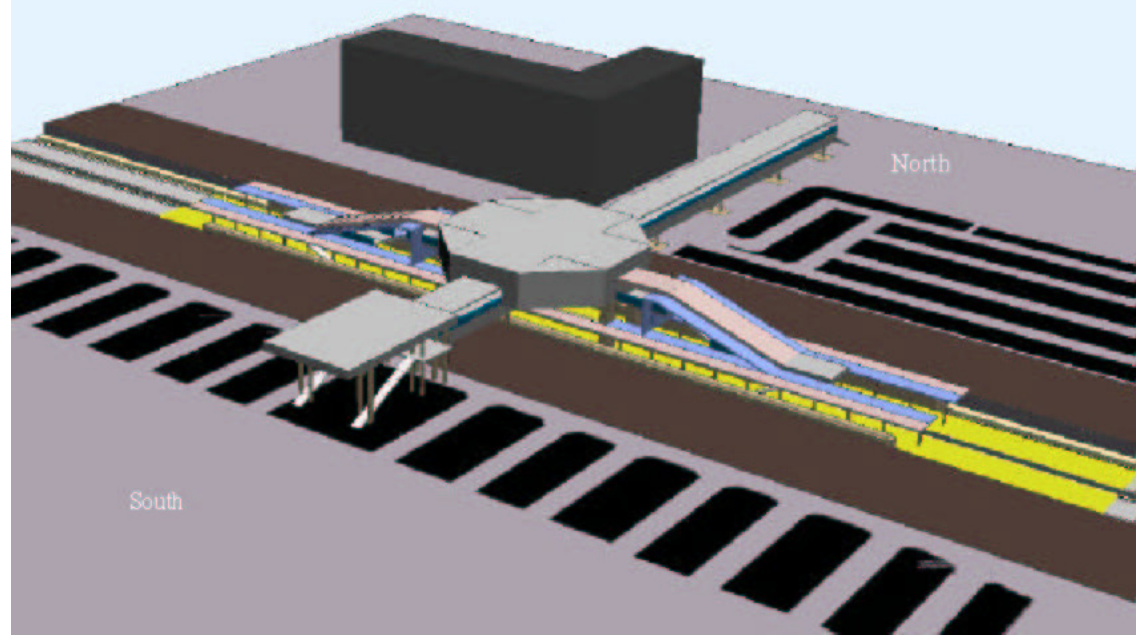

Figure 1: Isometric view of the Athens-Greece train station (viewing in the North West direction).

\subsubsection{Baseline results}

The CO levels along the train platform are well below the limit of $25 \mathrm{ppm}$. The maximum level in the platform area is $0.5 \mathrm{ppm}$. The following figures show the airflow patterns around the train station and $\mathrm{CO}$ level plots with an external wind speed of $15 \mathrm{~m} / \mathrm{s}$ from the North.

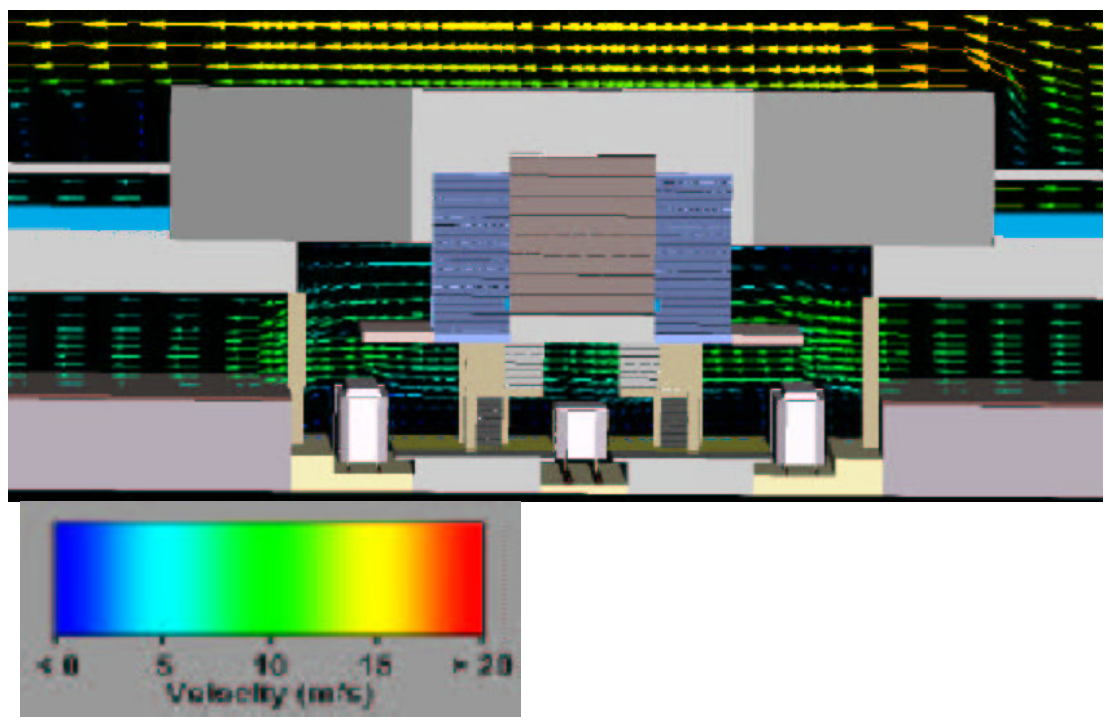

Figure 2: Airflow velocity plot through the center of the building (viewing in the West direction). 


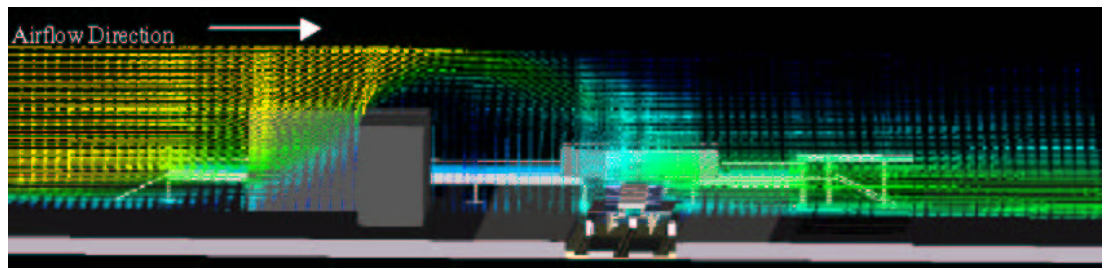

Figure 3: Airflow velocity plot across the Hotel (viewing in the East direction).

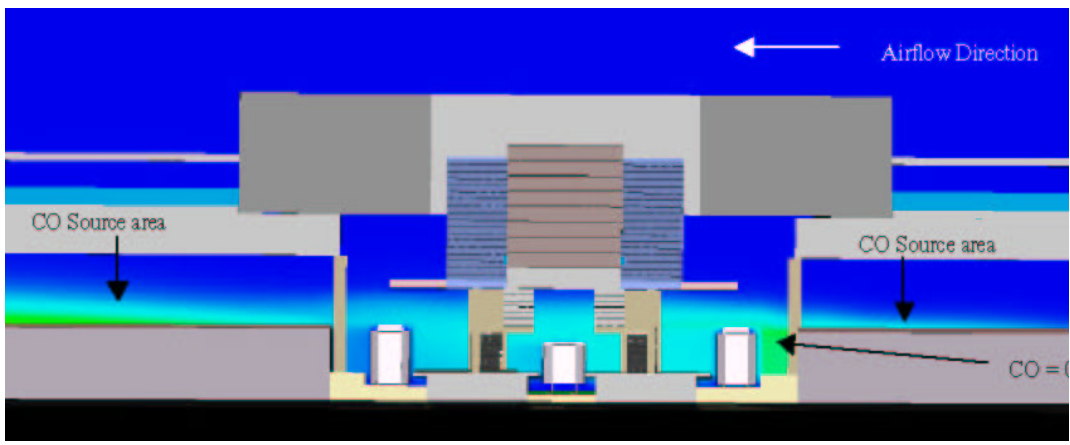

Figure 4: $\quad \mathrm{CO}$ plot through the center of the building showing the platform area. The maximum platform $\mathrm{CO}$ level is $0.2 \mathrm{ppm}$.

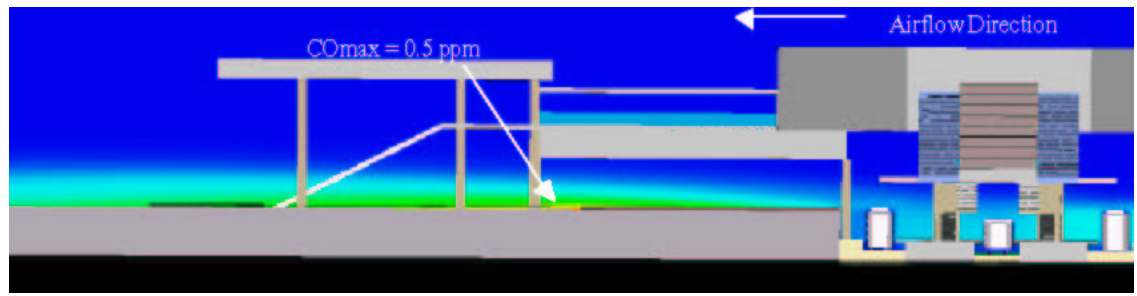

Figure 5: $\mathrm{CO}$ plot through the center of the building. The maximum $\mathrm{CO}$ level is $0.5 \mathrm{ppm}$ along the ground below the Southern walkway.

\subsubsection{Baseline case with different external conditions}

Three additional Iterations were studied and compared to the Baseline results to determine the affect on the $\mathrm{CO}$ levels at the train station platform. The results are summarized in the following Table.

In all cases analyzed, the maximum $\mathrm{CO}$ levels are outside of the train platform area and are well below the limit of $25 \mathrm{ppm}$. The location of the maximum $\mathrm{CO}$ varies depending upon the wind direction. The $\mathrm{CO}$ levels along 
the train platform are, also, well below the limit (more than 5 times lower than the limit of $25 \mathrm{ppm})$.

Table 1: $\quad$ Summary of CO levels with different wind conditions.

\begin{tabular}{|l|l|l|l|}
\hline Case & Summary of Results & & COmax (ppm) \\
\hline & & COmax $(\mathbf{p p m})$ & above the platform \\
\hline Baseline & $15 \mathrm{~m} / \mathrm{s}$ North direction & 0.5 & 0.2 \\
\hline Iteration 1 & $15 \mathrm{~m} / \mathrm{s}$ West direction & 1.1 & 0.15 \\
\hline Iteration 2 & $1 \mathrm{~m} / \mathrm{s}$ West direction & 16.5 & 2.2 \\
\hline Iteration 3 & $1 \mathrm{~m} / \mathrm{s}$ North direction & 7.9 & 2.8 \\
\hline
\end{tabular}

The following $\mathrm{CO}$ plots show the results of the Baseline and Iteration 1-3. The plots are $2 \mathrm{~m}$ above the train station platform.

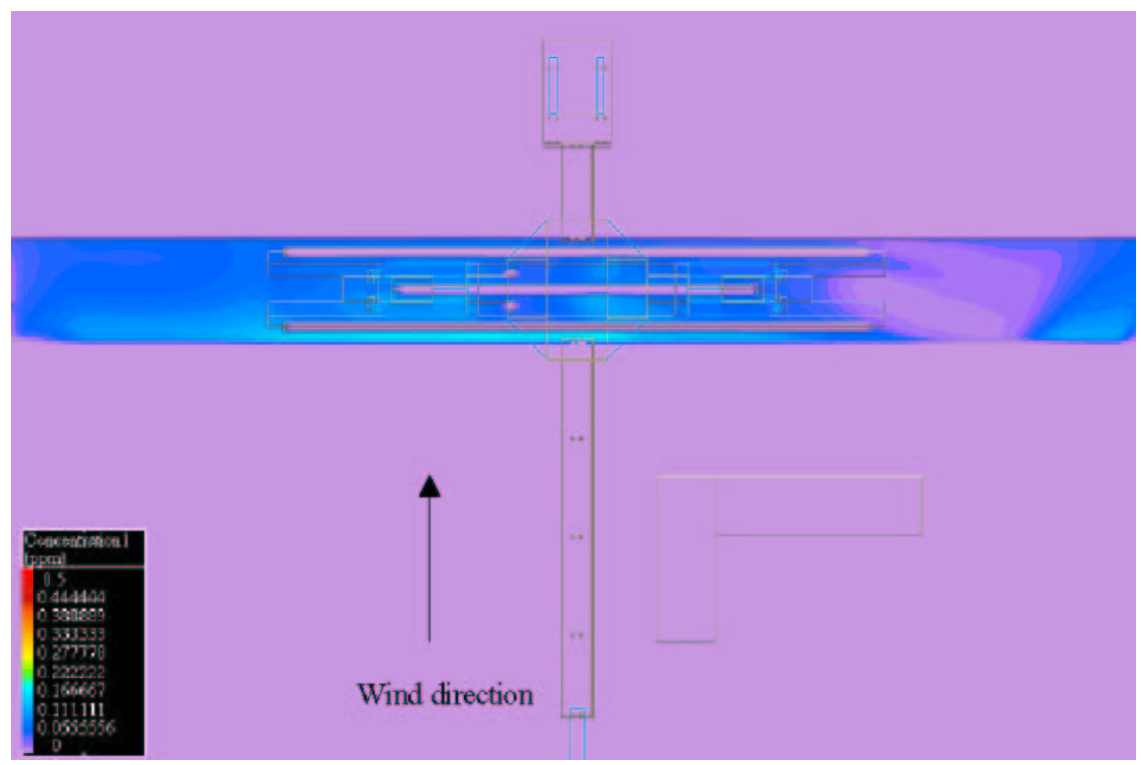

Figure 6: $\mathrm{CO}$ plot at $2 \mathrm{~m}$ height from the platform. North wind direction at $15 \mathrm{~m} / \mathrm{s}$. The maximum $\mathrm{CO}$ level on this plane is $0.2 \mathrm{ppm}$.

\subsection{Mechanical venting case}

\subsubsection{Model assumptions}

- The wind speed is $1 \mathrm{~m} / \mathrm{s}$ from the North direction. A velocity profile was applied at the North face of the solution domain, which varied from $0.1 \mathrm{~m} / \mathrm{s}$ at ground to $1 \mathrm{~m} / \mathrm{s}$ at $10 \mathrm{~m}$.

- Ambient temperature is $32^{\circ} \mathrm{C}$.

- Total CO release rate is $1.9 \mathrm{E}-3 \mathrm{~kg} / \mathrm{s}$. 
- 400 cars are releasing $\mathrm{CO}$ at a rate $2.61 \mathrm{~g} / \mathrm{mile}$.

- The CO source was uniformly distributed along the roadways.

- Small items, which do not affect the general airflow patterns, were not included in the model.

- Thermal loading from lights, people, trains, etc, were considered insignificant and were not included.

- The CFD solution domain size is $350 \mathrm{~m}$ x $350 \mathrm{~m}$ × $50 \mathrm{~m}$ with 920,856 grid cells. The maximum aspect ration is 15.6.

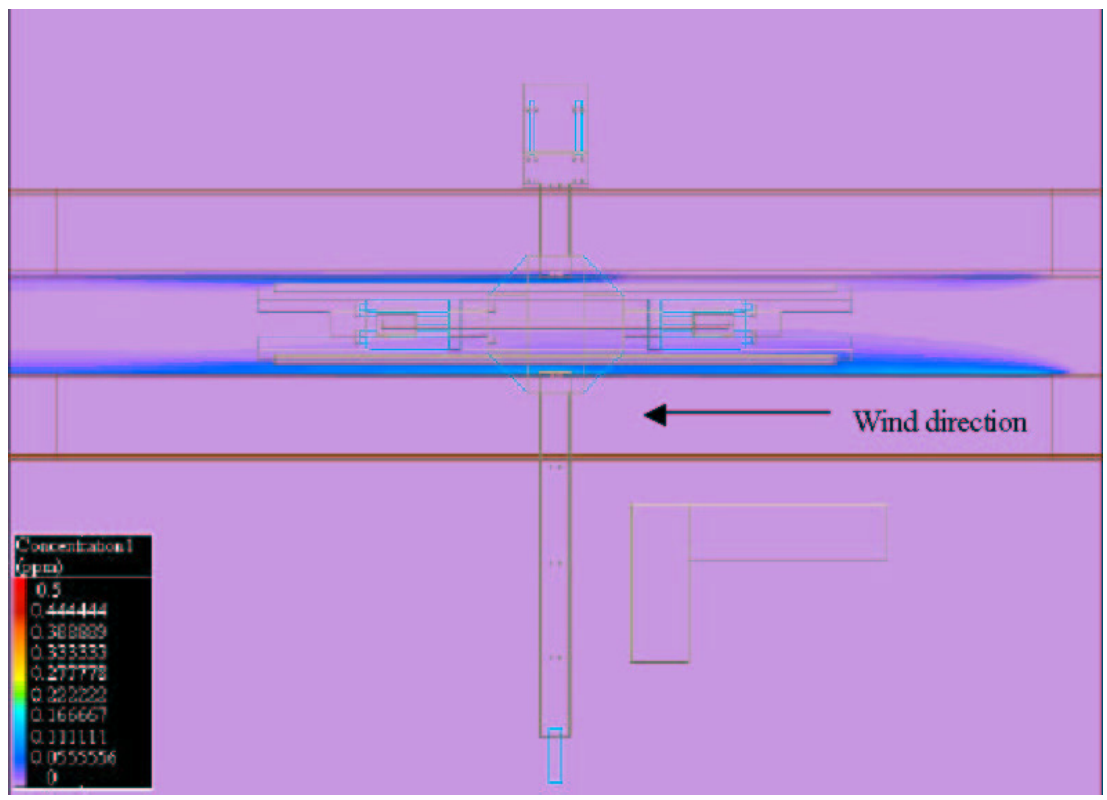

Figure 7: Iteration $1-\mathrm{CO}$ plot at $2 \mathrm{~m}$ height from the platform. West wind direction at $15 \mathrm{~m} / \mathrm{s}$. The maximum $\mathrm{CO}$ level on this plane is $0.15 \mathrm{ppm}$.

The model was solved on a system with dual 2.4 GHz CPUs and 2.0 G RAM. The model solved in approximately 750 iterations and in 8.2 hours.

\subsubsection{Model geometry}

The model geometry and Autocad drawings for the Mechanical Venting Case are shown in the figure 10.

Figures 11 and 12 compare the $\mathrm{CO}$ distribution along the train station platform with the same wind conditions with the venting on and off. The CO plot with venting on shows less dispersion of $\mathrm{CO}$ along the platform. There are regions where the $\mathrm{CO}$ levels are approximately $1.5 \mathrm{ppm}$ without the venting and these are below $1 \mathrm{ppm}$ when the venting is on. The following table shows the maximum $\mathrm{CO}$ levels for all cases analyzed. 


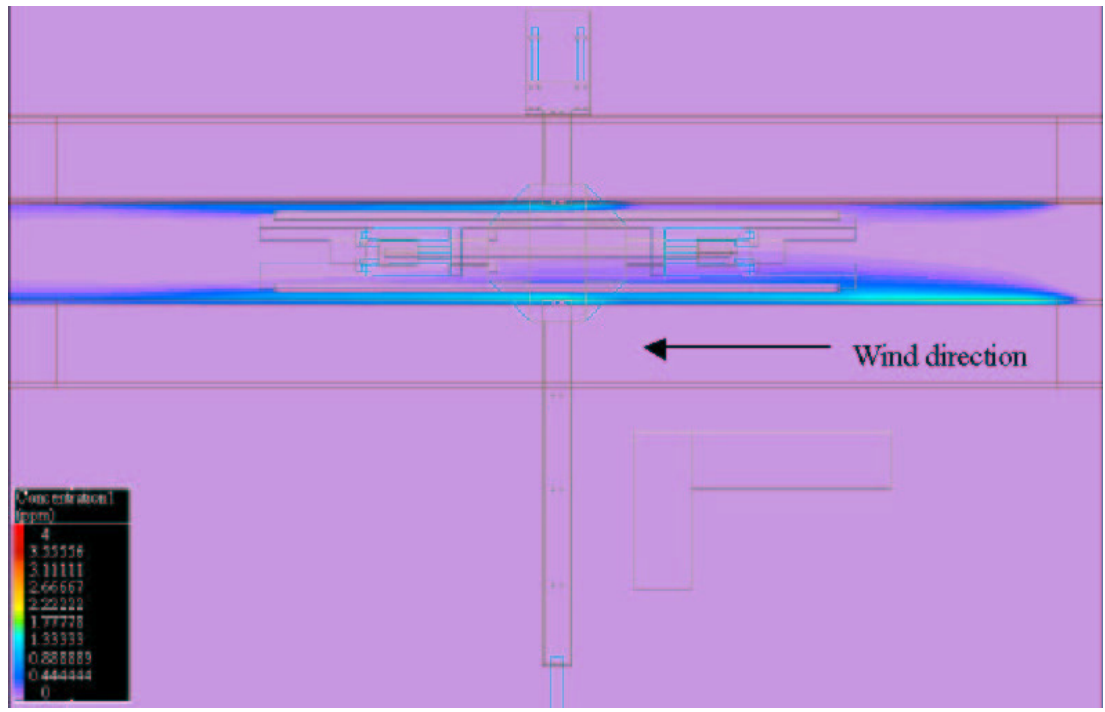

Figure 8: Iteration 2 - $\mathrm{CO}$ plot at $2 \mathrm{~m}$ height from the platform. West wind direction at $1 \mathrm{~m} / \mathrm{s}$. The maximum $\mathrm{CO}$ level on this plane is $2.2 \mathrm{ppm}$.

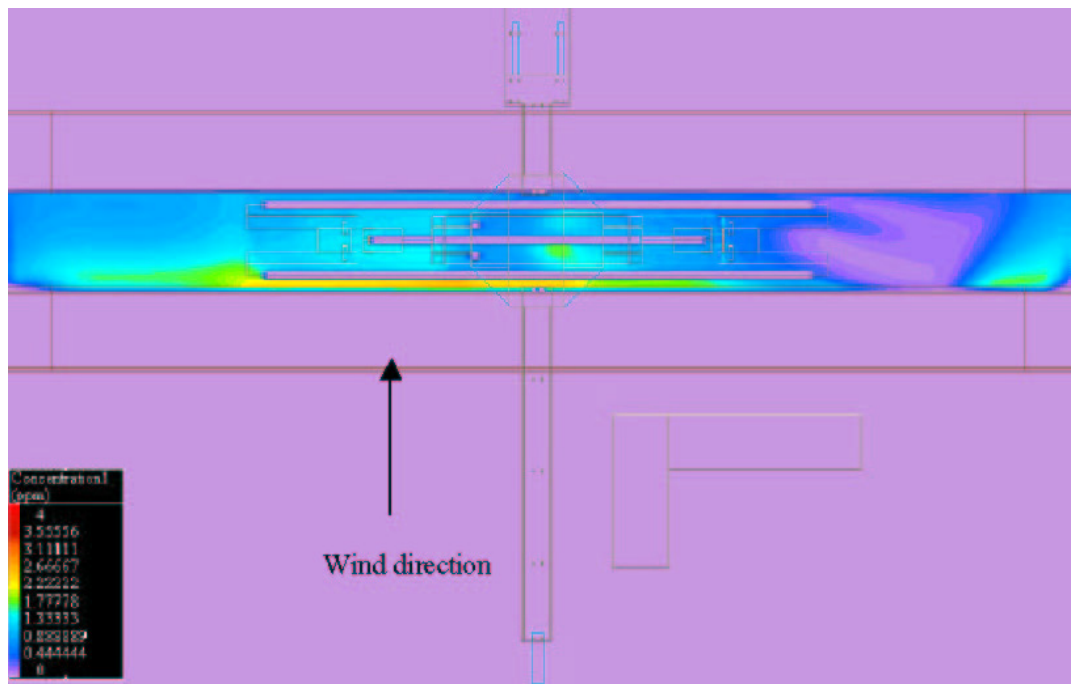

Figure 9: Iteration 3 - CO plot at $2 \mathrm{~m}$ height from the platform. North wind direction at $1 \mathrm{~m} / \mathrm{s}$. The maximum $\mathrm{CO}$ level on this plane is $2.8 \mathrm{ppm}$. 


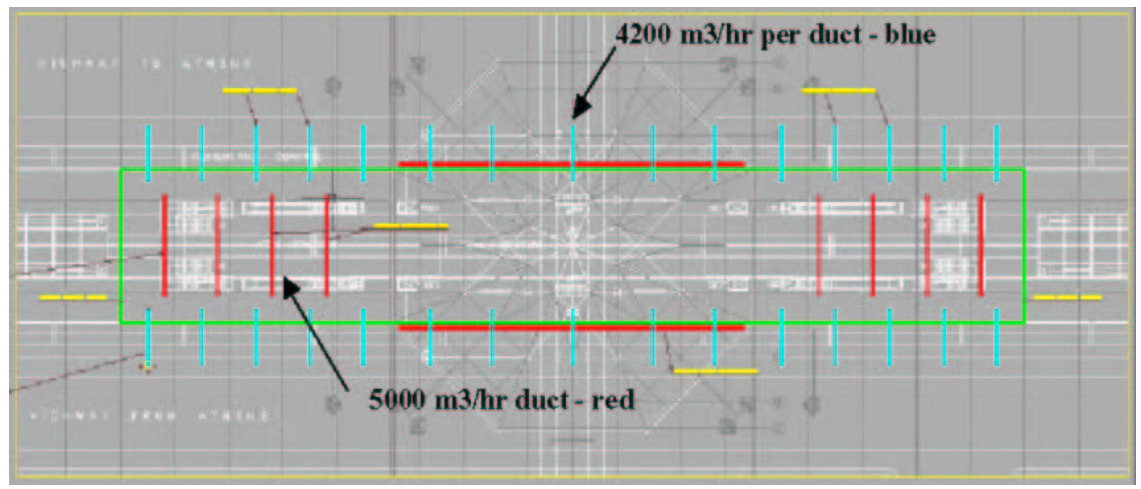

Figure 10: $\quad$ Plan view of the mechanical venting location and flow rates.

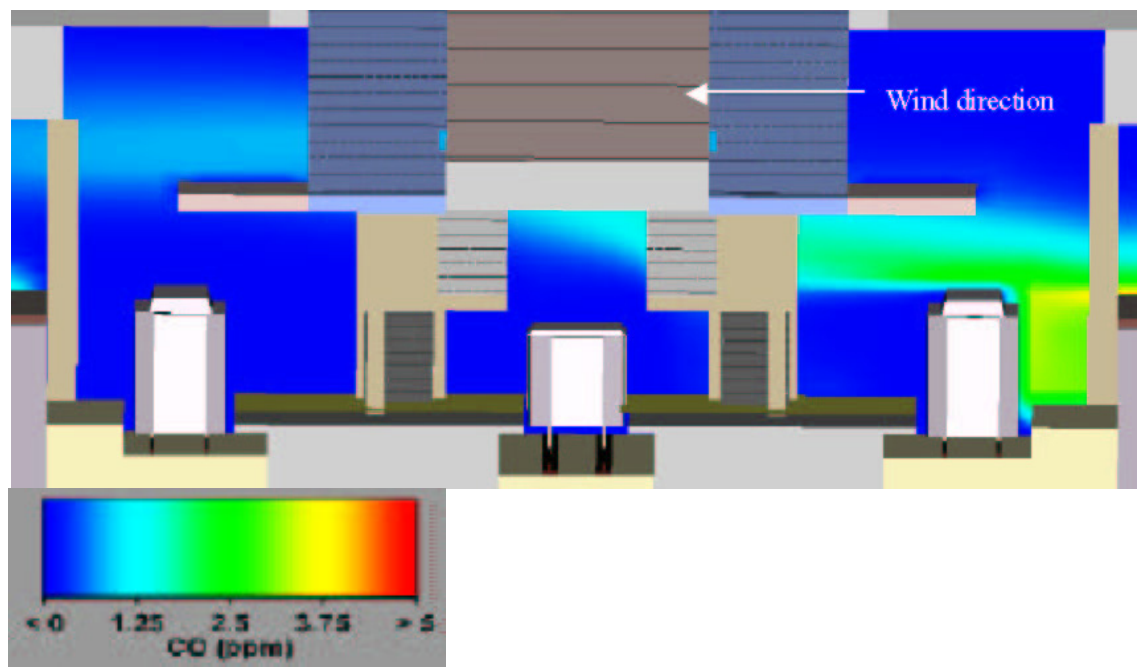

Figure 11: CO plot across the centreline on the platform with a $1 \mathrm{~m} / \mathrm{s}$ North wind and mechanical venting.

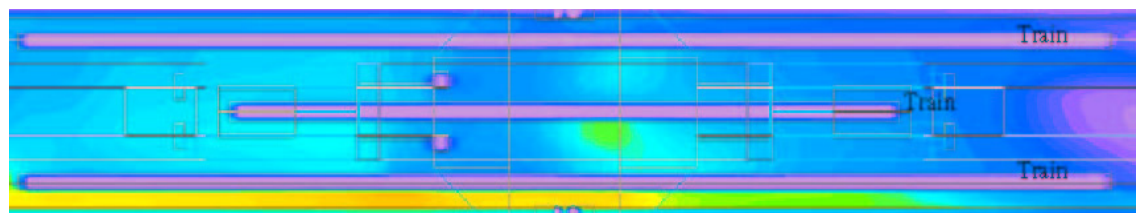

Figure 12: Plan view CO plot of Iteration $3-1 \mathrm{~m} / \mathrm{s}$ North wind; no venting.

The maximum $\mathrm{CO}$ levels for scenario 4 are higher than a similar case (Scenario 3) without venting. This is due to recirculation zones in Scenario 4, which created increased levels of $\mathrm{CO}$ in the platform area. Overall, the average $\mathrm{CO}$ levels are less at the platform with the ventilation on. 


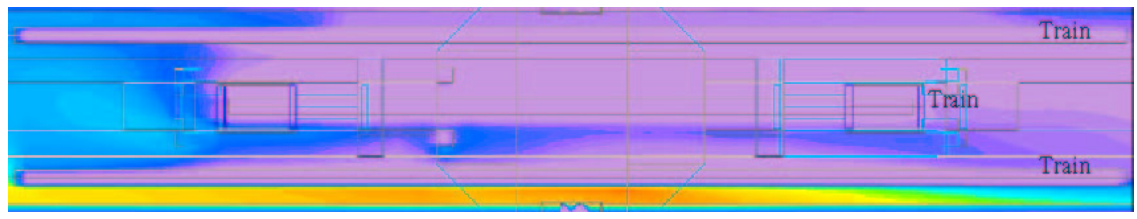

Figure 13: Plan view CO plot of Iteration $4-1 \mathrm{~m} / \mathrm{s}$ North wind; with venting.

Table 2: $\quad$ Summary of CO levels with different wind conditions - all cases.

\begin{tabular}{|l|l|c|c|}
\hline Case & Summary of Results & $\begin{array}{l}\text { COmax } \\
\text { ppm) }\end{array}$ & $\begin{array}{l}\text { COmax (ppm) } \\
\text { above platform }\end{array}$ \\
\hline Baseline & $15 \mathrm{~m} / \mathrm{s}$ North direction off & 0.5 & 0.2 \\
\hline Scenario 1 & $15 \mathrm{~m} / \mathrm{s}$ West direction off & 1.1 & 0.15 \\
\hline Scenario 2 & $1 \mathrm{~m} / \mathrm{s}$ West direction off & 16.5 & 2.2 \\
\hline Scenario 3 & $1 \mathrm{~m} / \mathrm{s}$ North direction off & 7.9 & 2.8 \\
\hline Scenario 4 & $1 \mathrm{~m} / \mathrm{s}$ North direction on & 9.7 & 3.4 \\
\hline
\end{tabular}

\section{Conclusions}

Airflow modelling of the Athens-Greece Train Station was performed to determine the $\mathrm{CO}$ levels along the train platform. The $\mathrm{CO}$ levels from the baseline model and four simulation scenarios are well below the $25 \mathrm{ppm}$ limit, that is the upper limit for long-term exposure (i.e. $8 \mathrm{hrs}$ ) as per World Health Organization Recommendations. These simulations included different wind speeds and direction, as well as, one Scenario with mechanical ventilation. The average $\mathrm{CO}$ levels at the platform with the ventilation on have decreased when compared to a similar case without ventilation under the same external wind conditions.

\section{Acknowledgement}

This publication was accomplished in the framework of Archimedes II-Support of Research Programs ЕПЕАЕК II.

\section{References}

[1] Krarti and Ayari, "Overview of Existing Regulations for Ventilation Requirements of Enclosed Vehicular Parking Facilities”, ASHRAE paper 4274 (RP-945), 1999, 105, page 6.

[2] Patankar, S V, "Numerical Heat Transfer and Fluid Flow", Hemisphere Publishing Corporation.

[3] Weather forecast data from the Athens airport whether forecast station.

[4] Weather forecast data from the central Athens whether forecast station. 